\title{
Extracellular vesicle-delivered miR-505-5p, as a diagnostic biomarker of early lung adenocarcinoma, inhibits cell apoptosis by targeting TP53AIP1
}

\author{
HUA FANG ${ }^{1-3}$, YUTAO LIU ${ }^{4}$, YAOHONG HE ${ }^{5}$, YANG JIANG ${ }^{6}$, \\ YAPING WEI ${ }^{2}$, HAN LIU $^{2}$, YUEQING GONG ${ }^{7}$ and GUANGYU AN ${ }^{1}$
}

\begin{abstract}
${ }^{1}$ Department of Oncology, Beijing Chao-Yang Hospital, Capital Medical University, Beijing 100020;
${ }^{2}$ Department of Oncology; ${ }^{3}$ Central Laboratory, Fuxing Hospital, The Eighth Clinical Medical College, Capital Medical University, Beijing 100038; ${ }^{4}$ Department of Medical Oncology, National Cancer Center/National Clinical Research Center for Cancer/Cancer Hospital, Chinese Academy of Medical Sciences and Peking Union Medical College, Beijing 100021; Departments of ${ }^{5}$ Respiratory Medicine and ${ }^{6}$ Thoracic Surgery, Fuxing Hospital, The Eighth Clinical Medical College, Capital Medical University, Beijing 100038; ${ }^{7}$ Key Laboratory of Cell Proliferation and Regulation Biology,

Ministry of Education, College of Life Sciences, Beijing Normal University, Beijing 100875, P.R. China
\end{abstract}

Received August 30, 2018; Accepted January 25, 2019

DOI: $10.3892 /$ ijo. 2019.4738

\begin{abstract}
Lung adenocarcinoma (LA) is the most commonly occurring histological type of non-small cell lung cancer. Diagnosis and treatment of LA remain a major clinical challenge. In the present study, to identify early LA biomarkers, extracellular vesicles (EVs) were separated from the plasma samples from 153 patients with LA and 75 healthy controls. microRNA (miRNA) expression profiling was performed at the screening stage (5 patients with LA vs. 5 controls), followed by verification at the validation stage ( 40 patients with LA vs. 20 controls) using reverse transcription-quantitative polymerase chain reaction (RT-qPCR). The four disordered miRNAs (miR-505-5p, miR-486-3p, miR-486-3p and miR-382-3p) identified in the plasma EVs were further evaluated at the testing stage (108 patients with LA vs. 50 controls) by RT-qPCR. It was revealed that miR-505-5p was upregulated, whereas miR-382-3p was downregulated, in the EVs from patients with LA. Furthermore, miR-505-5p was also upregulated in tumor tissues, compared with adjacent non-tumor control tissues. Subsequently, the direct targets of
\end{abstract}

Correspondence to: Dr Guangyu An, Department of Oncology, Beijing Chao-Yang Hospital, Capital Medical University, 8 Gongren Tiyuchang Nanlu, Chaoyang, Beijing 100020, P.R. China

E-mail: anguangyu@hotmail.com

Abbreviations: LA, lung adenocarcinoma; NSCLC, non-small cell lung cancer; EV, extracellular vesicle; RT-qPCR, reverse transcription-quantitative polymerase chain reaction; 3'-UTR, 3'-untranslated region; miRNA, microRNA

Key words: lung adenocarcinoma, miRNA, extracellular vesicle
miR-505-5p were predicted using bioinformatics analyses, and verified by luciferase assay and immunoblotting. The present study determined that miR-505-5p functions as an oncogene, promoting lung cancer cell proliferation and inhibiting cancer cell apoptosis via the targeting of tumor protein P53-regulated apoptosis-inducing protein 1 (TP53AIP1). Finally, it was confirmed that miR-505-5p in plasma EVs could be delivered to lung cancer cells, inhibiting cell apoptosis and promoting cell proliferation by targeting TP53AIP1. In conclusion, the present study indicated that miRNA-505-5p functions as an oncogene that may be used as a novel biomarker for the diagnosis and treatment of LA.

\section{Introduction}

Lung cancer is one of the most common malignancies globally, and is responsible for $>1,700,000$ estimated mortalities in 2018 globally (1). Lung adenocarcinoma (LA) is the most commonly occurring histological type of lung cancer, accounting for $\sim 40 \%$ of all lung cancer cases in China in 2010 (2). An investigation of the underlying molecular mechanisms and clinical features of LA has resulted in the development of novel markers and therapies for the diagnosis and treatment of different stages of LA $(3,4)$. However, numerous patients with LA are diagnosed at the advanced disease stage, due to a lack of effective approaches; therefore, the 5-year overall survival rate for patients with LA remains low (3). Currently, low-dose computed tomography is the recommended method of choice for screening early-stage lung cancer in high-risk populations, based on a previously published clinical study (5). However, potential false positive tests, over-diagnosis and psychosocial consequences limit its clinical applicability (6). The investigation of classical protein biomarkers, including carcinoembryonic antigen and cytokeratin 19 fragments, are commonly recommended in LA diagnosis and management (7). 
However, the sensitivity of these tumor markers is dependent on the prevalence rates of lung cancer, and the cut-off value differs in different populations $(8,9)$. Therefore, reliable and effective biomarkers in detecting early-stage LA are urgently required.

Extracellular vesicles (EVs), which are released from cells, are small membrane particles, ranging from 40 to $1,000 \mathrm{~nm}$ in diameter, and contain complex molecules, including nucleic acids, proteins and lipids (10). EVs are heterogeneous in size, density, subcellular origin and function, and are classified into the main two subtypes of exosomes and microvesicles (11). EVs, particularly exosomes, are produced by almost all types of cells in the human body, and are secreted into various human body fluids, including blood, saliva, pleural effusion, urine and breast milk (12). A previously published study has demonstrated that abnormal cell-cell communication contributes to carcinogenesis (13); furthermore, the microenvironment of tumors is essential for their rapid proliferation and metastasis to lymph nodes and organs (14). EVs fulfill roles in tumor occurrence, development and survival (15). Previous studies indicated that abnormal microRNA (miRNA) levels identified in EVs from patients with lung cancer, as well as cancer cell-delivered miRNAs or proteins through EVs, promote neighboring cell proliferation and migration $(16,17)$. miRNAs form a series of regulators that repress gene expression following transcription by binding directly to the 3'-untranslated regions (UTRs) of target mRNAs $(18,19)$. For cells, the levels of endogenous miRNAs may be changed when the microenvironment is altered (19-21). Furthermore, altered miRNA profiles have been implicated in human diseases, ranging from psychiatric disorders to malignant tumors (22-24). It is increasingly evident that miRNAs may be sorted into EVs, particularly exosomes, in which they are protected from degradation by ribonucleases; additionally, miRNAs serve important roles in tumorigenesis. However, an assessment of the roles of miRNAs in EVs remains in its infancy, and additional, more functional studies are required in order to delineate the complex roles of dysregulated miRNAs.

In the present study, patients with LA were assessed, and a three-stage study was developed, which may be used to examine relative plasma EV miRNA levels for the diagnosis of early-stage LA. The quantities of plasma EV miRNAs were detected on the basis of high-throughput sequencing and reverse transcription-quantitative polymerase chain reaction (RT-qPCR). Subsequently, the identified plasma EV miRNAs were verified in LA tissue samples, and compared with those in peripheral plasma samples. Additionally, an EV miRNA with altered levels was identified in the patients with LA as a potential, specific and minimally invasive biomarker for early clinical diagnosis of LA. Furthermore, subsequent functional studies demonstrated that miR-505-5p in EVs could be delivered into LA cells, inhibiting cell apoptosis and promoting cell proliferation by targeting tumor protein P53-regulated apoptosis-inducing protein 1 (TP53AIP1).

\section{Materials and methods}

Participants and samples. A total of 153 patients with LA (age range, 41-78 years; mean, 65.29 years; males, 88; and females, 65) and 75 healthy participants (age range,
43-78 years; mean, 57.35 years; males, 35; and females, 40) were recruited at Fuxing Hospital, Capital Medical University (Beijing, China) between February 2017 and May 2018. All the cases of LA were histopathologically confirmed, and diagnosed as stage I/II. The basis for clinical staging of LA was the eighth edition of the Union for International Cancer Control Tumor-Node-Metastasis system (25). Healthy controls involved in the present study were members of a healthy population undergoing routine medical examination at Fuxing Hospital, Capital Medical University. Healthy participants who had a history of acute or chronic pneumonia were excluded, as well as those with increased levels of serum tumor markers, or an abnormal chest imaging examination that had identified features such as small nodules, fibrous stripes or ground glass opacity in the lung.

The present study was approved by the Human Basic and Clinical Research Ethics Committee of Fuxing Hospital (approval no. 2018FXHEC-KY-19). All participants provided written informed consent prior to sampling.

The present study was divided into three stages, including the screening ( 5 patients with LA vs. 5 controls), validation (40 patients with LA vs. 20 controls) and testing (108 patients with LA vs. 50 controls) stages. The level of miR-505-5p and miR-382-3p were also examined in different clinical samples, including plasma EV, raw plasma, and LA and adjacent non-tumor tissue samples.

Blood samples $(10 \mathrm{ml})$ from patients with LA and the healthy controls prior to initial treatment were collected in commercially available ethylenediaminetetraacetic acid-treated tubes. Cells were removed from the plasma samples by centrifugation for $10 \mathrm{~min}$ at $1,000 \times \mathrm{g} 4^{\circ} \mathrm{C}$ using a refrigerated centrifuge (Becton Dickinson; Becton, Dickinson and Company, Franklin Lakes, NJ, USA). Platelets were depleted by centrifugation for $15 \mathrm{~min}$ at $2,000 \mathrm{x} \mathrm{g} 4^{\circ} \mathrm{C}$ from the plasma samples. The supernatant obtained following these two centrifugation steps was the standard plasma. The samples were separated out into $0.5 \mathrm{ml}$ aliquots and stored at $-80^{\circ} \mathrm{C}$. A total of 40 paired LA and adjacent non-tumor tissue samples were collected from surgical patients who had not received preoperative chemoradiotherapy and stored in liquid nitrogen $\left(-196^{\circ} \mathrm{C}\right)$.

Isolation of plasma EVs. EVs were extracted from plasma samples using a PuroExo ${ }^{\circledR}$ exosome isolation kit (101Bio; Thermo Fisher Scientific, Inc., Waltham, MA, USA), following the manufacturer's protocol. Briefly, debris was removed from the plasma samples by centrifugation for $15 \mathrm{~min}$ at $3,000 \mathrm{x} \mathrm{g}$ at $4^{\circ} \mathrm{C}$. The supernatant was diluted by the addition of $500 \mu \mathrm{l}$ sample buffer (provided in the kit) to the supernatant, prior to mixing with $250 \mu \mathrm{l}$ prepared mixture reagent (provided in the kit). After vortex-mixing for $10 \mathrm{sec}$ at $25^{\circ} \mathrm{C}$, the mixture was incubated for $30 \mathrm{~min}$ at $4^{\circ} \mathrm{C}$ followed by centrifugation at $3,000 \mathrm{x} \mathrm{g}$ at $4^{\circ} \mathrm{C}$ for $2 \mathrm{~min}$, and the samples were then divided into 3 layers. The middle, 'fluffy' layer was transferred to a fresh tube and centrifuged at 5,000 x g at $4^{\circ} \mathrm{C}$ for $3 \mathrm{~min}$. Subsequently, a new 3-layer separation appeared and only the middle 'fluffy' layer was retained. A total of $500 \mu$ l PBS was added to the fluffy pellets, and the resuspended solution was then centrifuged $5,000 \times \mathrm{g}$ at $4^{\circ} \mathrm{C}$ for $3 \mathrm{~min}$. The supernatant was placed into a PuroExo ${ }^{\circledR}$ column and centrifuged for $5 \mathrm{~min}$ 
at $3,000 \mathrm{x}$ at $4^{\circ} \mathrm{C}$. The flow-through comprised the isolated pure exosomes.

Transmission electron microscopy. A solution of $2 \%$ paraformaldehyde was prepared to fix the EVs at $4^{\circ} \mathrm{C}$ for $10 \mathrm{~min}$, and subsequently $5 \mu \mathrm{l} \mathrm{EV}$ suspension was transferred to each carbon-coated 200 mesh copper grid. Adsorption was allowed to occur for $5 \mathrm{~min}$ at $4^{\circ} \mathrm{C}$. The grids were washed twice with PBS, followed by 8 washes with deionized water. The grids were counterstained with uranyl acetate $(2 \%)$ for $1 \mathrm{~min}$ at $4^{\circ} \mathrm{C}$, and subsequently air-dried. Negative staining of EVs was observed on the basis of their shape, structure and size using a Philips CM12 transmission electron microscope at x80,000 magnification (Philips Research China, Ltd., Shanghai, China).

Nanoparticle-tracking analysis. Size distribution and concentration of the EVs were measured using ZetaView ${ }^{\circledR}$ nanoparticle-tracking analysis instrumentation (Particle Metrix, Meerbusch, Germany). Briefly, after isolation from the plasma, diluted EVs samples were added to the measurement system. Particle size distribution was calculated on the basis of the Brownian motion of individual particles, according to the Stokes-Einstein equation (26).

RNA extraction and RT-qPCR. Total RNA from plasma EVs or the plasma of patients with LA and the healthy controls, or frozen tissues of patients with LA, or cell lines (including A549, H1299 and 293T cells) was extracted using a miRNeasy Mini kit (Qiagen, Inc., Valencia, CA, USA). For EVs and plasma RNA extraction, Cel-miR-39 was added into the samples prior to extraction as external control. RT-qPCR was applied to detect the relative expression levels of selected miRNAs. RNA was reverse-transcribed using an Applied Biosystems ${ }^{\mathrm{TM}}$ TaqMan ${ }^{\circledR}$ MicroRNA Reverse Transcription kit and amplified with Applied Biosystems TaqMan Universal PCR Master mix, together with miRNA-specific Applied Biosystems TaqMan MGB probes (labeled by fluorescein and minor groove binder; Applied Biosystems; Thermo Fisher Scientific, Inc.), according to the manufacturer's protocol. The quantity of RNA and its purity were measured on a Nanodrop Technologies ND-2000 spectrophotometer (Thermo Fisher Scientific, Inc.). Only samples with the appropriate absorbance measurements $\left(\mathrm{A}_{260} / \mathrm{A}_{280}\right.$ of $\sim 2.0$, and $\mathrm{A}_{260} / \mathrm{A}_{230}$ of 1.9-2.2) were considered for inclusion in the present study. The reaction conditions were as follows: $95^{\circ} \mathrm{C}$ for $10 \mathrm{~min}$, followed by 40 cycles of $95^{\circ} \mathrm{C}$ for $15 \mathrm{sec}$ and $60^{\circ} \mathrm{C}$ for $1 \mathrm{~min}$. In order to compare the miRNA levels between different samples, the $2^{-\Delta \Delta \mathrm{Cq}}$ method was used (27). Primers sequences are detailed in Table I. Plasma EVs and plasma samples were normalized against Cel-miR-39, whereas cell lines and frozen tissues were normalized to U6. A total of three triplicate experiments were performed in each case.

According to the high-through sequencing results, the top 5 upregulated miRNAs and top 5 downregulated miRNAs were firstly detected in the plasma EVs from a cohort consists of 40 patients with LA vs. 20 controls. Subsequently, four significantly-altered miRNAs were selected for the testing stage, for validation in 108 patients with LA and 50 matched controls.
High-throughput sequencing. A total amount of $1 \mu \mathrm{g}$ total RNA per sample was used as input material for the small RNA library. NEBNext ${ }^{\circledR}$ Multiplex Small RNA Library Prep Set for Illumina ${ }^{\circledR}$ (New England BioLabs, Inc., Ipswich, MA, USA) was used to generate the sequencing libraries. The clustering of index-coded samples was performed on a cBot Cluster Generation system with TruSeq SR Cluster kit, v3-cBot-HS (Illumina Inc., San Diego, CA, USA), according to the manufacturer's protocol. Subsequently, the library was subjected to an Illumina HiSeq 2500/2000 platform for sequencing, and 50 bp single-end reads were generated. Raw data were first processed through custom Perl and Python scripts. Clean data (clean reads) were read by removing reads containing poly-N with 5'-adapter contaminants, without $3^{\prime}$ adapter or the insert tag, or containing poly-A or $-\mathrm{T}$ or $-\mathrm{G}$ or $-\mathrm{C}$ from raw data, as well as low-quality reads. Q20, Q30 and the GC content of raw data were then calculated. Subsequently, a certain range (18-40 nucleotides) of length from clean reads was selected for downstream analyses. After unpaired Student's t-test analysis, the top 5 upregulated miRNAs and top 5 downregulated miRNAs in the EVs from patients with LA were selected for further assessment.

MicroRNA targets prediction and gene ontology analysis. The direct targets of miR-505-5p were predicted using TargetScan 7.0 (http://www.targetscan.org/vert_70/). The top 1,000 predicted target genes were subjected to Gene Ontology analysis. The Gene Ontology analysis was processed with DAVID Bioinformatics Resources 6.8 (https://david.ncifcrf. gov/).

Cell culture. A549, H1299 and 293T cells purchased from the China Infrastructure of Cell Line Resources (Institute of Basic Medical Sciences, Chinese Academy of Medical Sciences, Beijing, China) were cultured in Dulbecco's modified Eagle's medium (DMEM) supplemented with $10 \% \mathrm{HyClone}^{\mathrm{TM}}$ fetal bovine serum (FBS) (Hyclone; GE Healthcare Life Sciences, Logan, UT, USA), $100 \mathrm{U} / \mathrm{ml}$ penicillin and $100 \mathrm{U} / \mathrm{ml}$ streptomycin at $37^{\circ} \mathrm{C}$ in a humid atmosphere containing $5 \% \mathrm{CO}_{2}$. For the cell proliferation and apoptosis assay experiments, exosome-depleted FBS (Systems Biosciences, Palo Alto, CA, USA) was used for cell culture.

Cell transfection. A549 and H1299 cells (1x105) were seeded into 6-well plates 1 day prior to transfection. The cells were transfected with $25 \mathrm{nM}$ miR-505 mimic or inhibitor (Shanghai GenePharma Co., Ltd., Shanghai, China) with Invitrogen Lipofectamine ${ }^{\circledR} 2000$ reagent (Invitrogen; Thermo Fisher Scientific, Inc.), according to the manufacturer's protocol. After $48 \mathrm{~h}$ following transfection, the transfection efficiency was determined by RT-qPCR, as aforementioned. The miR-505 mimic is a double strand RNA oligo, with sequence scrambled double strand RNA oligo as control. Furthermore, the miR-505 inhibitor is a single strand RNA oligo, with sequence scrambled single strand RNA oligo as control. The sequences for miR-505 mimic, inhibitor and corresponding control are: miR-505 mimic, 5'-GGGAGCCAGGAAGUAUUGAUGU-3'; mimic control, 5'-AGUGUUGGACUAAGCGGAGGUA-3'; miR-505 inhibitor, 5'-ACAUCAAUACUUCCUGGCUCCC-3'; and inhibitor control, 5'-UAACACGUCUAUACGCCCA-3'. 
Table I. Primers sequences.

\begin{tabular}{|c|c|}
\hline Primer name & Sequences \\
\hline UP-R & 5'-GTGCAGGGTCCGAGGT-3' \\
\hline cel39-F & 5'-ACTCACCGGGTGTAAATCA-3' \\
\hline miR-16-F & 5'-GTCCAATATTACTGTGCTG-3' \\
\hline miR-495-F & 5'-GCAAACAAACATGGTGCAC-3' \\
\hline miR-194-F & 5'-GTTGTAACAGCAACTCCAT-3' \\
\hline $\operatorname{miR}-486-3 \mathrm{~F}$ & 5'-TACGGGGCAGCTCAGTAC-3' \\
\hline $\mathrm{miR}-486-5 \mathrm{~F}$ & 5'-TATCCTGTACTGAGCTGC-3' \\
\hline miR-505-F & 5'-ATGGGAGCCAGGAAGTATT-3' \\
\hline miR-126-F & 5'-CGTCGTACCGTGAGTAA-3' \\
\hline miR-382-F & 5'-CTAATCATTCACGGACAA-3' \\
\hline miR-410-F & 5'-GCAATATAACACAGATG-3' \\
\hline miR-411-F & 5'-CGTACGCTATACGGTCTACTA-3' \\
\hline cel39-RT & 5'-GTTGGCTCTGGTGCAGGGTCCGAGGTATTCGCACCAGAGCCAACCAAGCTG-3' \\
\hline miR-16-RT & 5'-GTTGGCTCTGGTGCAGGGTCCGAGGTATTCGCACCAGAGCCAACTAAAGCA-3' \\
\hline miR-495-RT & 5'-GTTGGCTCTGGTGCAGGGTCCGAGGTATTCGCACCAGAGCCAACAAGAAGT-3' \\
\hline miR-194-RT & 5'-GTTGGCTCTGGTGCAGGGTCCGAGGTATTCGCACCAGAGCCAACTCCACAT-3' \\
\hline miR-486-3RT & 5'-GTTGGCTCTGGTGCAGGGTCCGAGGTATTCGCACCAGAGCCAACATCCTGT-3' \\
\hline $\operatorname{miR}-486-5 \mathrm{RT}$ & 5'-GTTGGCTCTGGTGCAGGGTCCGAGGTATTCGCACCAGAGCCAACCTCGGGG-3' \\
\hline miR-505-RT & 5'-GTTGGCTCTGGTGCAGGGTCCGAGGTATTCGCACCAGAGCCAACACATCAA-3' \\
\hline miR-126-RT & 5'-GTTGGCTCTGGTGCAGGGTCCGAGGTATTCGCACCAGAGCCAACCGCATTA-3' \\
\hline miR-382-RT & 5'-GTTGGCTCTGGTGCAGGGTCCGAGGTATTCGCACCAGAGCCAACAAGTGT-3' \\
\hline miR-410-RT & 5'-GTTGGCTCTGGTGCAGGGTCCGAGGTATTCGCACCAGAGCCAACACAGGC-3' \\
\hline miR-411-RT & 5'-GTTGGCTCTGGTGCAGGGTCCGAGGTATTCGCACCAGAGCCAACCGTACG-3' \\
\hline
\end{tabular}

miR, microRNA; F, forward; RT, reverse.

Co-culture of cells and exosomes. A549 and $\mathrm{H} 1299$ cells $\left(5 \times 10^{3}\right)$ were seeded into 96-well plates in DMEM supplemented with exosome-depleted FBS, $100 \mathrm{U} / \mathrm{ml}$ penicillin and $100 \mathrm{U} / \mathrm{ml}$ streptomycin, and the cells were incubated at $37^{\circ} \mathrm{C}$ overnight. EVs isolated from the plasma samples of 10 patients with LA and 10 control subjects were added into the cells at a final concentration of $100 \mu \mathrm{g} / \mathrm{ml}$ for $48 \mathrm{~h}$ at $37^{\circ} \mathrm{C}$ for co-cultivation.

Dual luciferase assay. A 221 bp fragment of the 3'-UTR from TP53AIP1 was cloned downstream of the firefly luciferase gene into a pmirGLO plasmid (Promega Corporation, Madison, WI, USA) to generate the reporter vector. miRNA mimic, miRNA inhibitor and sequence scrambled single- and double-strand control oligos were purchased from Shanghai GenePharma Co., Ltd. 293T cells were seeded into 48 -well plates at $5 \times 10^{4}$ cells/well, attached overnight for luciferase reporter assays. The reporter vector was co-transfected into cells with miRNA mimic or inhibitor using Invitrogen Lipofectamine 2000. At 2 days after transfection, the cells were lysed, and the luciferase activity was analyzed using a Dual-Luciferase ${ }^{\circledR}$ Reporter Assay System (Promega Corporation). Experiments were performed in triplicate, and the results were analyzed as the relative luciferase activity (firefly luciferase/Renilla luciferase).

Immunoblotting. Protein samples were quantified using a Pierce BCA Protein Assay kit (Pierce; Thermo Fisher
Scientific, Inc.), according to the manufacturer's protocols. Protein samples were heated with SDS sample buffer $(0.25 \mathrm{M}$ Tris- $\mathrm{HCl}, \mathrm{pH}$ 6.8, $0.5 \mathrm{M}$ DTT, $10 \%$ SDS, $50 \%$ glycerol and $0.5 \%$ bromophenol blue) at $95^{\circ} \mathrm{C}$ for $5 \mathrm{~min}$, A total of $30 \mu \mathrm{g}$ were loaded per lane and then separated on $15 \%$ SDS-PAGE and electroblotted onto polyvinylidene fluoride membranes (Amersham; GE Healthcare Life Sciences, Little Chalfont, UK). Subsequently, the membranes were incubated with anti-TP53AIP1 rabbit polyclonal antibody at a dilution of 1:1,000 (cat. no. ab217785; Abcam, Cambridge, MA, USA) and anti- $\beta$-actin mouse monoclonal antibody at a dilution of 1:3,000 (cat. no. sc-47778; Santa Cruz Biotechnology, Inc., Dallas, TX, USA) overnight at $4^{\circ} \mathrm{C}$. Immunoreactive bands were detected by incubation with horseradish peroxidase-conjugated goat anti-rabbit (cat. no. ab205718) or rabbit anti-mouse IgG (cat. no. ab6728; Abcam) at a dilution of 1:5,000 for $2 \mathrm{~h}$ at room temperature. Detection by chemiluminescence was performed using a Pierce enhanced chemiluminescence kit (Pierce; Thermo Fisher Scientific, Inc.).

Cell proliferation assay. The extent of cell proliferation was measured according to cell viability, which was evaluated using an MTT assay. Briefly, A549 and H1299 cells (5x10 $\left.{ }^{3}\right)$ were seeded into 96-well plates in DMEM and incubated at $37^{\circ} \mathrm{C}$ overnight. The cells were transfected with miR-505-inhibitor for $24 \mathrm{~h}$ using the same protocol as aforementioned. EVs of 
Table II. Characteristics of the 153 patients with lung adenocarcinoma and 75 healthy controls included in the present study.

\begin{tabular}{|c|c|c|c|}
\hline Study stage/variable & Case $(\%)$ & Control (\%) & P-value \\
\hline \multicolumn{4}{|c|}{ Screening (cohort, $n=10$ ) } \\
\hline Sex & & & 1.000 \\
\hline Male & $3(60)$ & $2(40)$ & \\
\hline Female & $2(40)$ & $3(60)$ & \\
\hline Age (mean $\pm \mathrm{SD})$ & $62.00 \pm 8.37$ & $58.40 \pm 15.77$ & 0.664 \\
\hline Smoking & & & 1.000 \\
\hline No & $2(40)$ & $3(60)$ & \\
\hline Yes & $3(60)$ & $2(40)$ & \\
\hline \multicolumn{4}{|c|}{ Validation cohort $(n=60)$} \\
\hline Sex & & & 0.409 \\
\hline Male & $24(60)$ & $9(45)$ & \\
\hline Female & $16(40)$ & $11(55)$ & \\
\hline Age $($ mean $\pm \mathrm{SD})$ & $64.06 \pm 9.27$ & $60.40 \pm 11.07$ & 0.221 \\
\hline Smoking & & & 0.370 \\
\hline No & $26(65 \%)$ & $16(80 \%)$ & \\
\hline Yes & $14(35 \%)$ & $4(20 \%)$ & \\
\hline \multicolumn{4}{|l|}{ Testing cohort $(\mathrm{n}=158)$} \\
\hline Sex & & & 0.411 \\
\hline Male & $61(60)$ & $24(45)$ & \\
\hline Female & $47(40)$ & $26(55)$ & \\
\hline Age $($ mean $\pm \mathrm{SD})$ & $63.60 \pm 8.96$ & $61.35 \pm 10.92$ & 0.439 \\
\hline Smoking & & & 0.684 \\
\hline No & $70(64.8)$ & $30(60)$ & \\
\hline Yes & $38(35.2)$ & $20(40)$ & \\
\hline
\end{tabular}

SD, standard deviation.

patients with LA or healthy control subjects were added in each well (final concentration, $100 \mu \mathrm{g} / \mathrm{l}$ ) $24 \mathrm{~h}$ after transfection, and the cells were subsequently incubated at $37^{\circ} \mathrm{C}$ for $48 \mathrm{~h}$. Aliquots $(20 \mu \mathrm{l})$ of MTT solution $(5 \mathrm{mg} / \mathrm{ml}$; Sigma-Aldrich; Merck KGaA, Darmstadt, Germany) were added to each well after co-cultivation, and the cells were further incubated at $37^{\circ} \mathrm{C}$ for $4 \mathrm{~h}$. The absorbance was read at $570 \mathrm{~nm}$ on a 96 -well plate reader following the addition of dimethyl sulfoxide.

Cell apoptosis assay. Cell apoptosis was assessed using flow cytometric analysis, following Annexin V-fluorescein isothiocyanate (FITC) and propidium iodide staining using a FITC Annexin V Apoptosis Detection kit (BioLegend, Inc., San Diego, CA, USA). Results were analyzed with a flow cytometer and FlowJo software (v10.4.1; Tree Star, Inc., Ashland, OR, USA).

Statistical analysis. Statistical analysis was performed using SPSS software version 19.0 (IBM Corp., Armonk, NY, USA) and data are presented as the mean \pm standard. Luciferase activity, and the cell apoptosis and proliferation data were analyzed by paired Student's t-test. The miRNA expression levels were evaluated by unpaired Student's t-test. Clinical characteristics were evaluated by the $\chi^{2}$ test. Receiver operating characteristic (ROC) curves were employed to measure the optimal cut-off value for each selected miRNA. The score for each miRNA was considered to be 1 for expression levels above the cutoff value; otherwise, it was set as 0 . The area under the ROC curve (AUC) was used to evaluate the diagnostic value of each selected miRNA in LA. Fisher's exact test was used for gene-enrichment analysis. $\mathrm{P}<0.05$ was considered to indicate a statistically significant difference.

\section{Results}

Identification of altered miRNAs in patients with LA. To identify altered levels of EV miRNAs in plasma from patients with early-stage LA, peripheral blood samples were collected from 153 patients with LA and 75 healthy participants. The present study was divided into three stages, including the screening, validation and testing stages. The clinical characteristics are detailed in Table II.

Plasma EVs were assessed by transmission electron microscopy and nanoparticle-tracking analysis. The results obtained revealed that the majority of the vesicles had the typical exosome size (28) (30-200 nm in diameter; Fig. 1A) and a bilayer membrane structure (Fig. 1B).

During the screening stage, the expression profile miRNAs was assessed based on high-throughput sequencing in 5 patients with LA and 5 matched healthy controls. The top 5 upregulated miRNAs (miR-486-3p, miR-194-5p, miR-486-5p, miR-16-3p and miR-505-5p) and top 5 downregulated miRNAs (miR-411-5p, miR-126-3p, miR-495-3p, miR-382-3p and miR-410-3p) (Fig. 2A) were selected for further assessment. In the validation stage, the 10 aforementioned miRNAs selected as candidate miRNAs were assessed using RT-qPCR, with a cohort consisting of 40 patients with LA and 20 matched healthy controls. As depicted in Fig. 2B, the levels of miR-486-3p, miR-486-5p and miR-505-5p in EVs were significantly increased in LA patients, compared with the control subjects $(\mathrm{P}=0.015, \mathrm{P}=0.011$ and $\mathrm{P}=0.031$, respectively). Furthermore, the plasma $\mathrm{EV}$ levels of miR-382-3p were significantly reduced in patients with LA, compared with control subjects $(\mathrm{P}=0.039)$.

Subsequently, these four miRNAs were selected for the testing stage, for validation in 108 patients with LA and 50 matched controls. As depicted in Fig. 3A, the miR-505-5p levels were significantly elevated in patients with $\mathrm{LA}(\mathrm{P}=0.015)$, whereas the levels of miR-382-3p were significantly reduced $(\mathrm{P}=0.031)$, compared with control subjects.

Diagnostic values of plasma EV miRNAs. To assess the performances of the two aforementioned EV miRNAs in distinguishing patients with LA from control subjects, optimal cut-off values for miR-505-5p and miR-382-3p in EVs were determined based on ROC curves in the testing cohort. As depicted in Fig. 3B, miR-505-5p had an AUC of 0.899 (95\% confidence interval, 0.826-0.974), with a sensitivity and specificity of 83.3 and $93.3 \%$, respectively; whereas, miR-382-3p exhibited an AUC of 0.851 (95\% confidence interval, 0.773-0.928), with a sensitivity and specificity of 81.5 and $71.1 \%$, respectively. Additionally, the two miRNAs in 


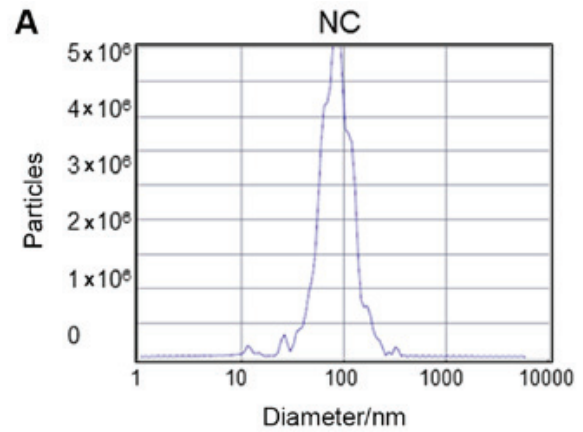

B

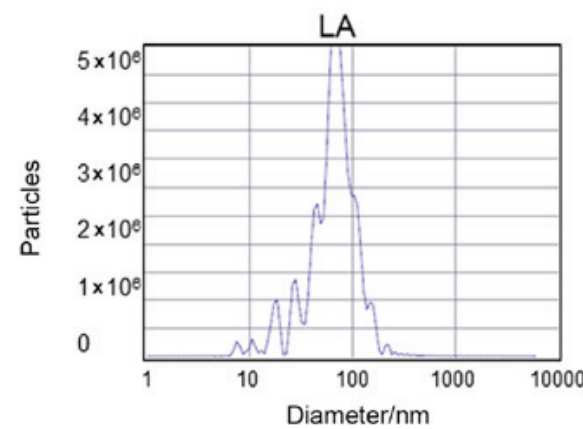

NC1

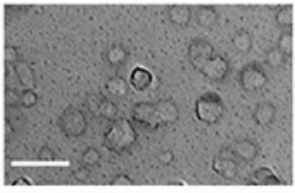

NC2

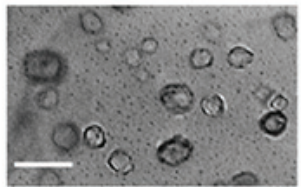

NC3

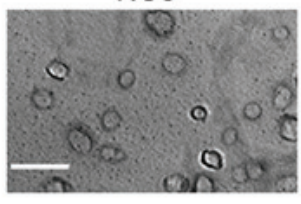

LA1

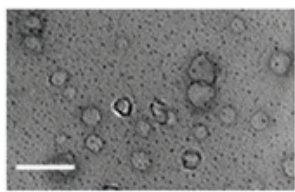

LA2

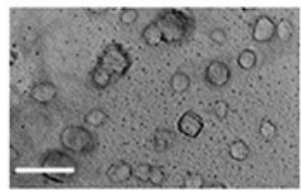

LA3

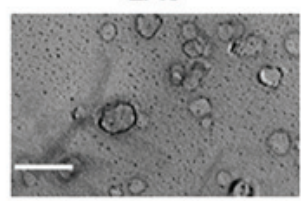

Figure 1. Isolation of extracellular vesicles from plasma. (A) Nanoparticle-tracking analysis of EVs from cases of LA and matched NC plasma samples, indicating the size distribution of the isolated particles. The majority of the particles were observed to have a typical exosome size (30-200 nm in diameter). (B) Transmission electron microscopy images of plasma-derived EVs (scale bar, $100 \mathrm{~nm}$ ). EV, extracellular vesicle; LA, lung adenocarcinoma; NC, normal control.

A

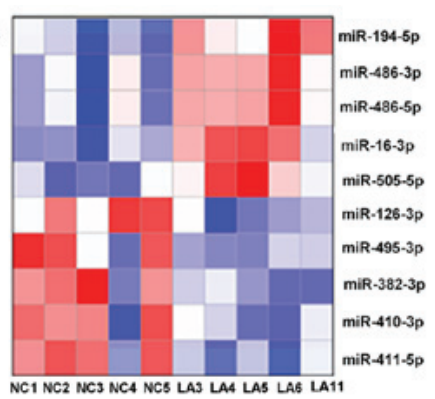

B
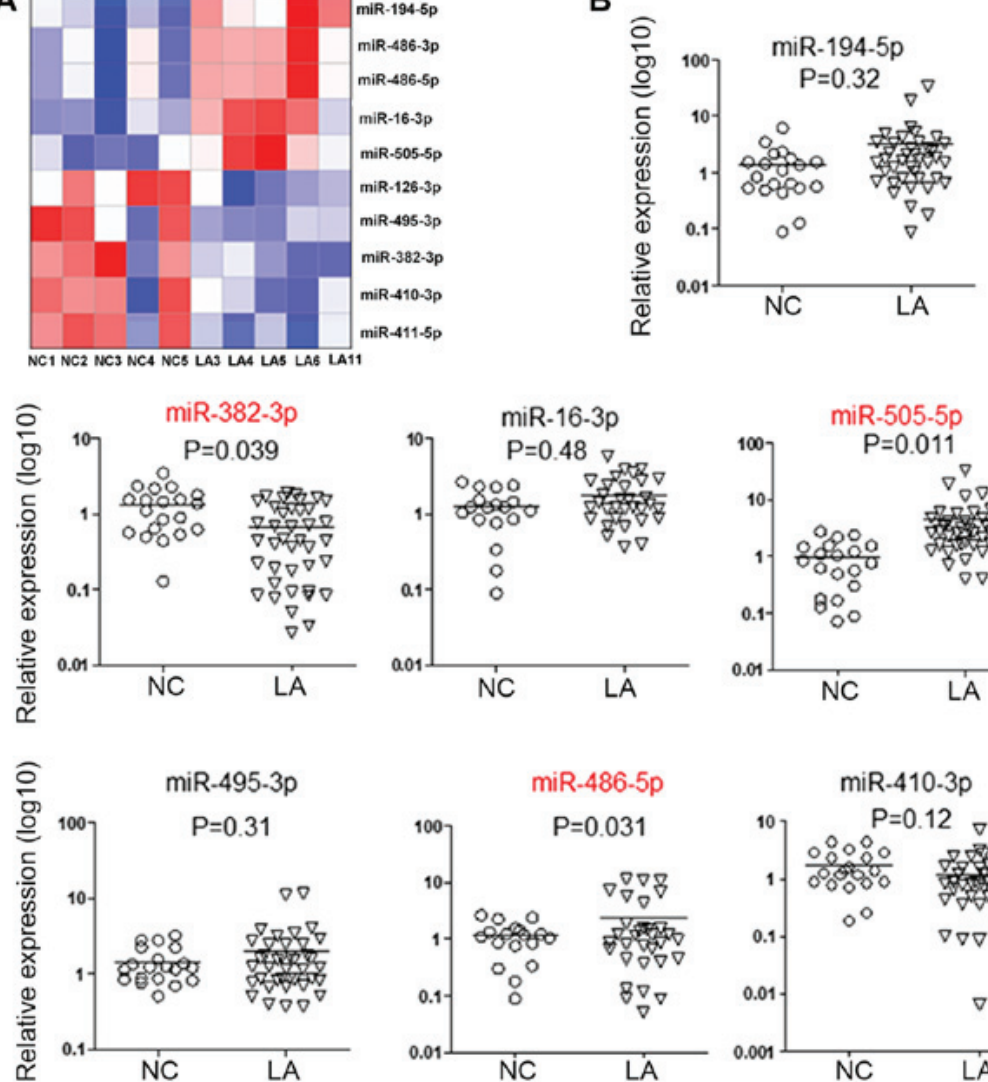
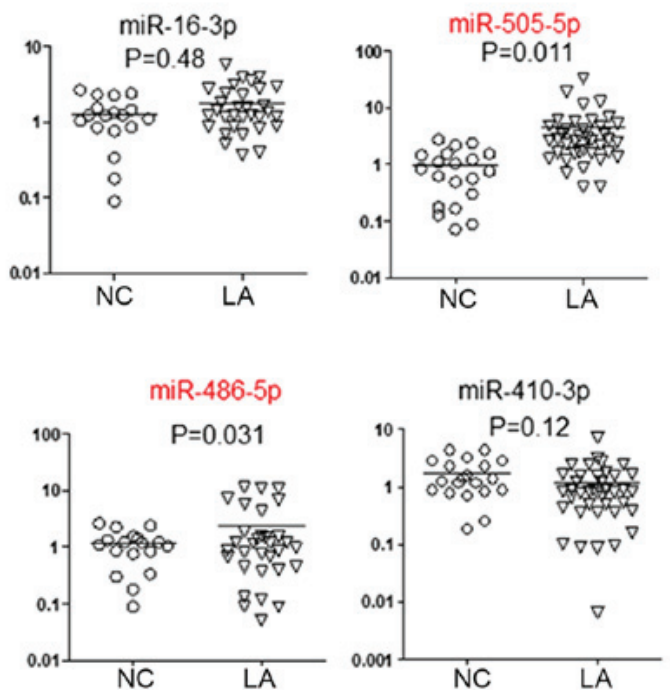
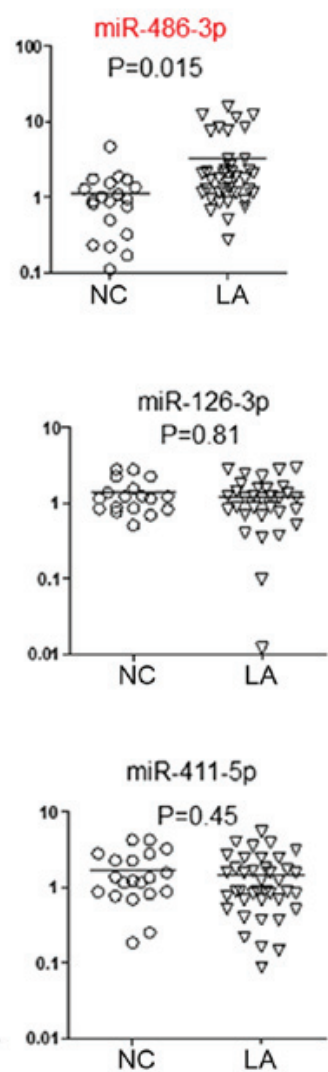

Figure 2. Altered miRNA levels in extracellular vesicles from patients with LA. (A) Hierarchical cluster analysis. Heat map illustrating miRNA samples from 5 patients with LA and 5 healthy NCs detected by high-throughput sequencing on an Illumina HiSeq 2500/2000 platform. The top 5 upregulated (miR-194-5p, miR-486-3p, miR-486-5p, miR-16-3p and miR-505-5p) and top 5 downregulated (miR-126-3p, miR-495-3p, miR-382-3p, miR-410-3p and miR-411-5p) miRNAs were selected. (B) The above 10 selected miRNAs were confirmed by reverse transcription-quantitative polymerase chain reaction in a cohort of 40 patients with LA and $20 \mathrm{NC}$ subjects. Results were normalized to the level of cel-miR-39, which was added into the samples as external control prior to RNA extraction. The levels of miR-505-5ps, miR-386-5p, miR-386-3p and miR-382-3p were significantly altered. $\mathrm{P}<0.05$ was considered to be statistically significant (unpaired Student's t-test). LA, lung adenocarcinoma; miRNA, microRNA; NC, normal control. 
A
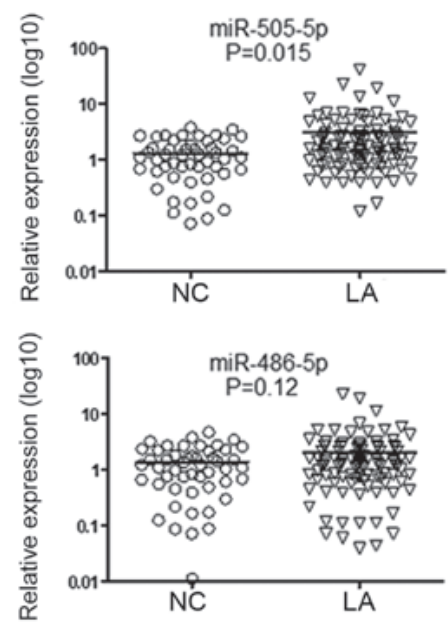
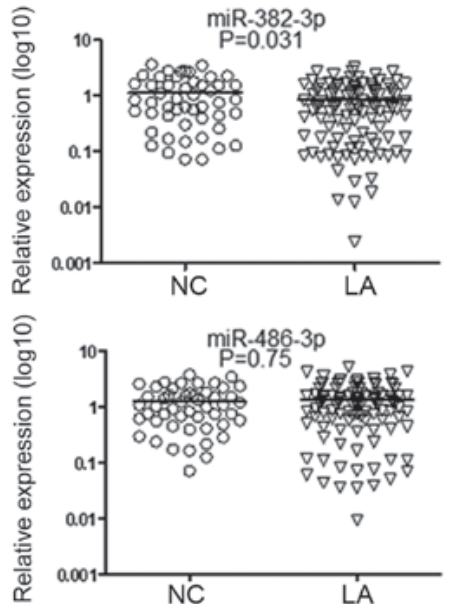
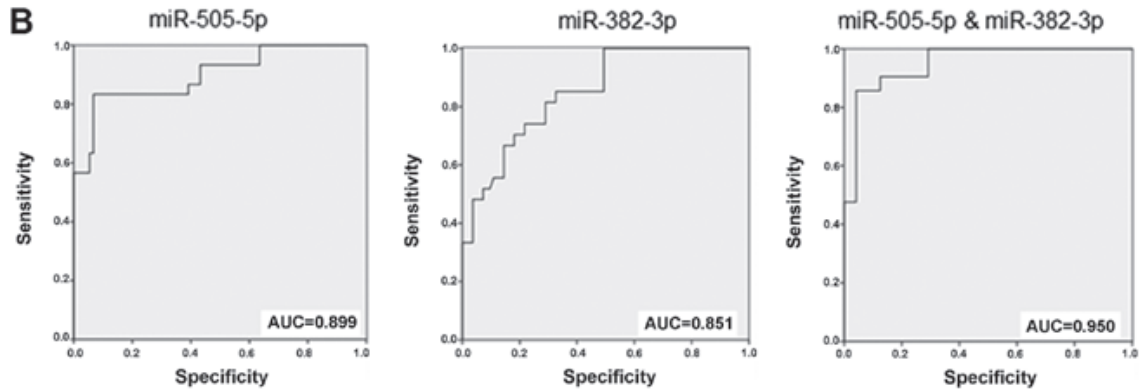

Figure 3. Expression levels of miR-505-5p and miR-382-3p in the testing cohort, and ROC curves for two miRNAs to distinguish patients with LA from healthy controls. (A) The levels of miR-505-5p, miR-386-5p, miR-386-3p and miR-382-3p were detected in extracellular vesicles from 108 patients with LA and 50 healthy NCs. Results were normalized to the level of cel-miR-39, which was added into the samples as external control prior to RNA extraction. $\mathrm{P}<0.05$ was considered to be statistically significant (unpaired Student's t-test). (B) ROC curves for miR-505-5p and miR-382-3p in testing a cohort consisting of 108 patients with LA and 50 healthy NCs. LA, lung adenocarcinoma; miRNA, microRNA; ROC, receiver operating characteristic; NC, normal control.

combination exhibited an increased ability to distinguish the two experimental groups, compared with either miRNA alone, with an AUC of 0.950 (95\% confidence interval, 0.906-0.995; sensitivity, $85.7 \%$; and specificity, $95.8 \%$ ).

Verification of miRNAs in tissue samples and plasma. To examine the expression pattern consistency of miR-505-5p and miR-382-3p in different clinical samples, the levels of miR-505-5p and miR-382-3p in plasma EV and raw plasma from a cohort comprising of 40 patients with LA and 40 controls were analyzed. Furthermore, the levels of these two miRNAs were also detected in 40 paired LA and adjacent non-tumor tissue samples.

As depicted in Fig. 4, the levels of miR-505-5p were statistically increased in plasma EVs. Furthermore, the levels of miR-505-5p were significantly increased in tumor samples, compared with the corresponding adjacent normal tissues, whereas the levels of miR-382-3p revealed no statistical differences between tumor and adjacent normal tissue specimens. Furthermore, only the levels of miR-505-5p in the plasma of patients with LA were significantly increased, compared with the control group.

Investigation of miR-505-5p function in lung cancer. To investigate miR-505-5p function in LA pathogenesis, the direct targets of miR-505-5p were first predicted with the TargetScan online bioinformatics tool. The top 1,000 predicted target genes were subjected to Gene Ontology analysis, and 9 of them were identified to be potentially involved in the cell apoptotic signaling pathway (Fig. 5), including TP53AIP1.

TP53AIP1 is a p53-inducible gene that serves an important role in mediating p53-dependent apoptosis (29). Although TP53AIP1 is predominantly expressed in the thymus, it is also detectable in the lungs, and reduced levels of TP53AIP1 in lung cancer tissues is considered to be a predictor of poor prognosis in patients with non-small cell lung cancer (NSCLC) $(30,31)$. Therefore, a $221 \mathrm{bp}$ fragment of the TP53AIP1 3'-UTR was subsequently cloned downstream of the firefly luciferase gene in the pmirGLO plasmid; additionally, a plasmid with 4 nucleotide mutations was also generated as the mutant reporter vector (Fig. 6A). As depicted in Fig. 6B, relative luciferase activity was significantly downregulated in cells treated with the miR-505-5p mimic, compared with control, whereas the luciferase activity was upregulated following transfection with the miR-505-5p inhibitor, compared with inhibitor control. By contrast, for the mutant reporter vector, which featured the 4 nucleotide mutations, relative luciferase activity was not significantly reduced by the miR-505-5p mimic, indicating that $\mathrm{miR}-505-5 \mathrm{p}$ inhibited luciferase expression by targeting the 3'-UTR of TP53AIP1. Subsequently, the miR-505-5p mimic and inhibitor were transfected into the human NSCLC cell lines, A549 and H1299 for $72 \mathrm{~h}$. TP53AIP1 protein levels then were assessed using immunoblotting. As depicted in Fig. 6C, TP53AIP1 protein expression was downregulated by the miR-505-5p mimic, and upregulated by the miR-505-5p inhibitor. Furthermore, the overexpression and knockdown, 


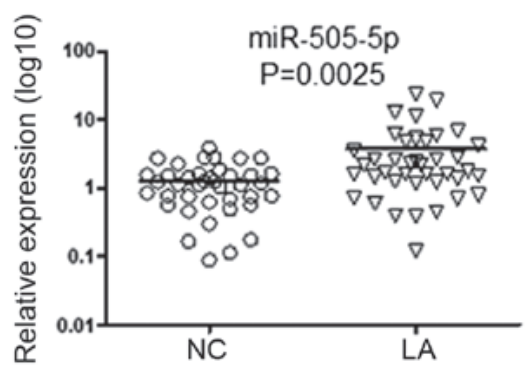

EVs
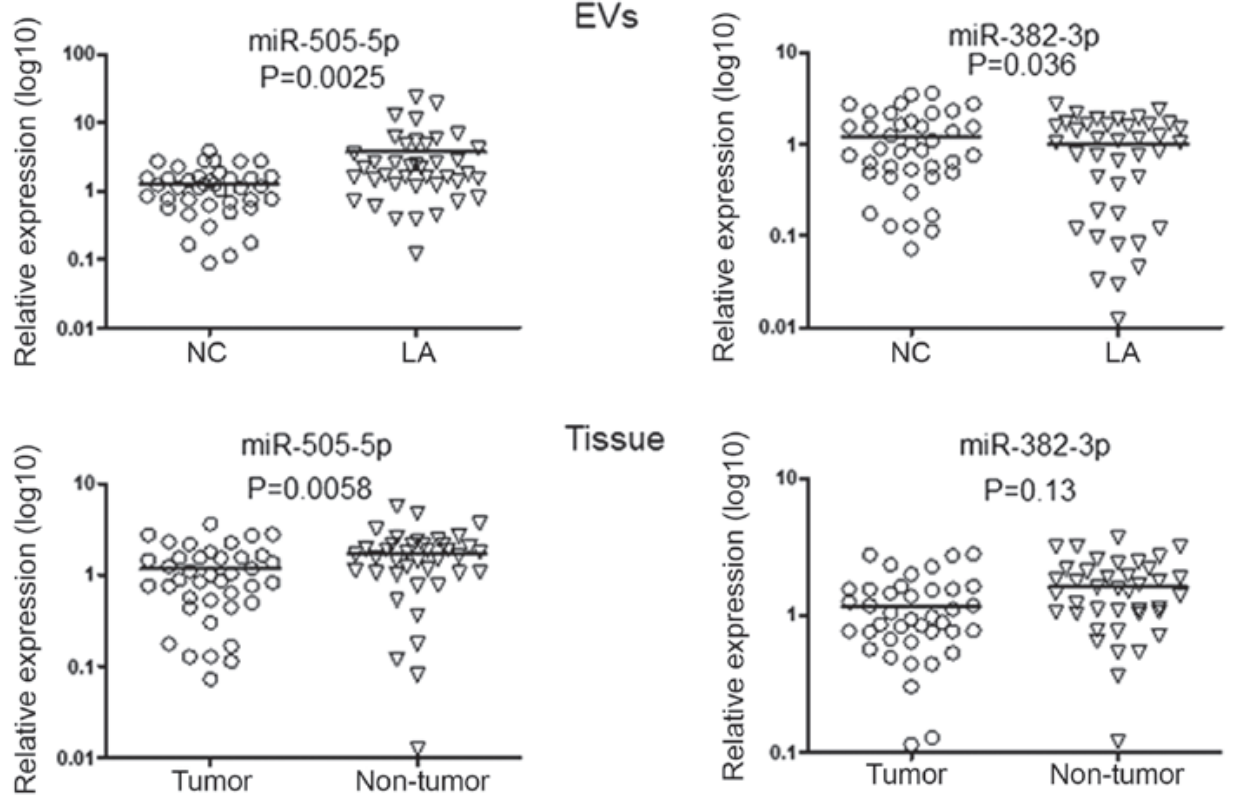

Tissue
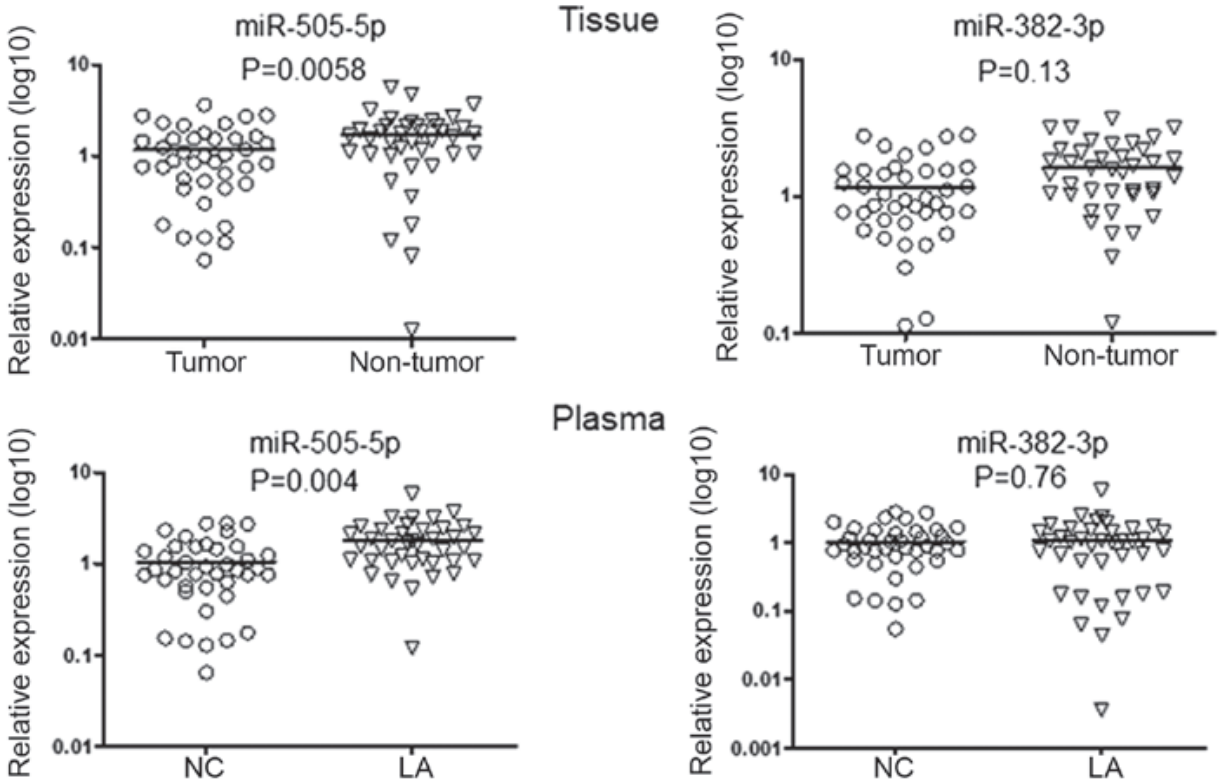

Figure 4. Levels of miR-505-5p and miR-382-3p in EVs, plasma and tissue samples from a cohort of 40 patients with LA and 40 NCs. EV, plasma and tissue samples were collected from a cohort of 40 patients with LA and $40 \mathrm{NCs}$, and subjected to RNA extraction. The levels of miR-505-5p and miR-382-3p were determined by reverse transcription-quantitative polymerase chain reaction. The miRNAs levels in EVs and plasma samples were normalized to the level of cel-miR-39, which was added into the samples as external control prior to RNA extraction. The miRNAs levels in tissue samples were normalized to U6. The results in EVs and plasma samples were analyzed using unpaired Student's t-test, and the results in tissue samples were analyzed using paired Student's t-test. $\mathrm{P}<0.05$ was considered to be statistically significant. LA, lung adenocarcinoma; EV, extracellular vesicle; NC, normal control; miRNA, microRNA.

\section{GO annotation}

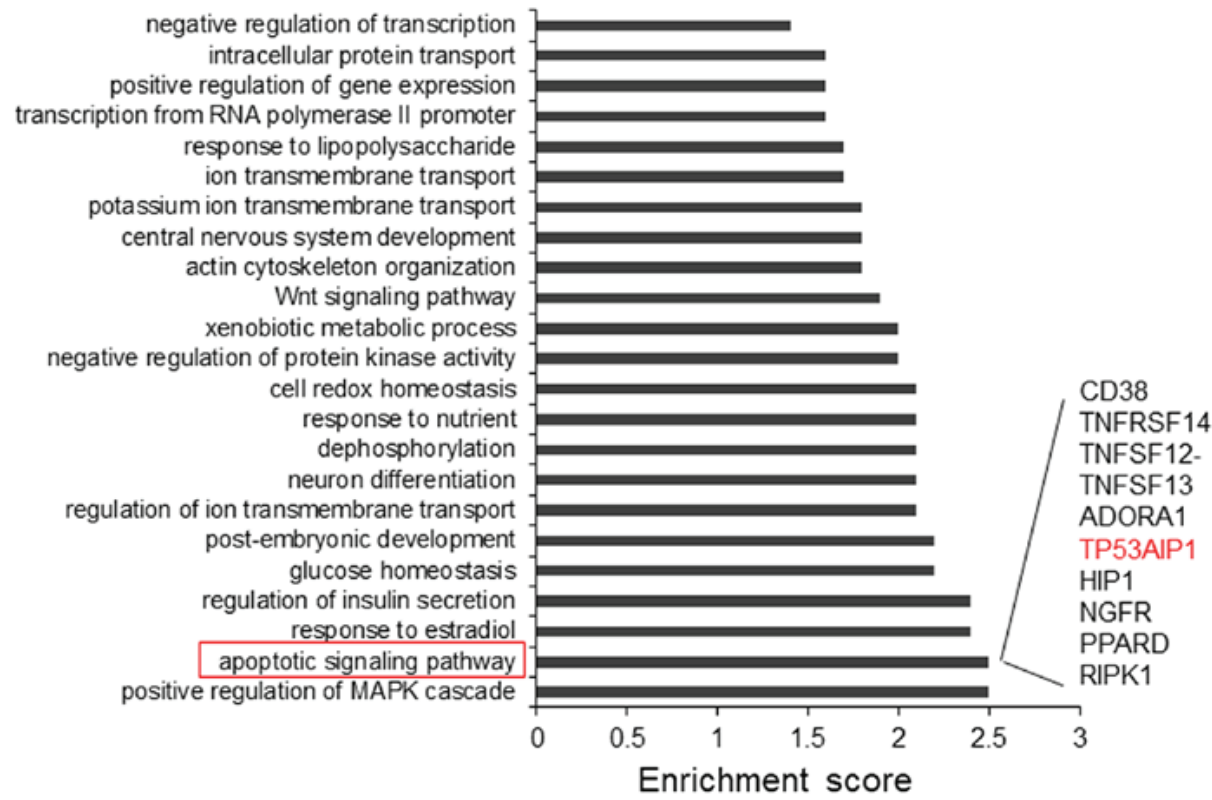

Figure 5. Target gene prediction and GO analysis. The direct targets of miR-505-5p were predicted using TargetScan 7.0, and GO analysis was processed with DAVID Bioinformatics Resources 6.8. Fisher's exact test was used for gene-enrichment analysis. GO, Gene Ontology; DAVID, Database for Annotation, Visualization and Integrated Discovery. 
A

\author{
Position 97-104 of TP53AIP1 3'UTR WT \\ hsa-miR-505-5p
}

Position 97-104 of TP53AIP1 3'UTR MUT

hsa-miR-505-5p

\section{B}

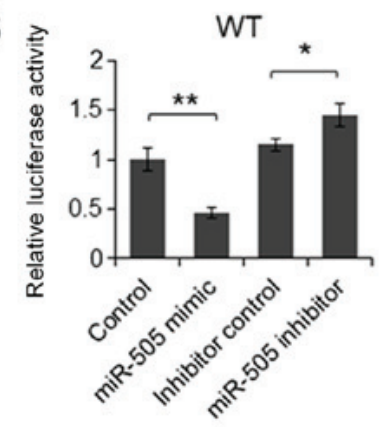

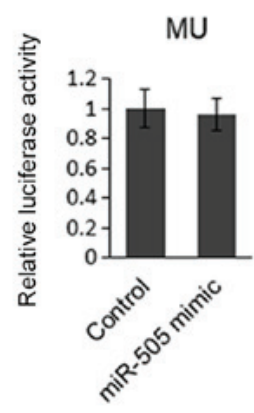

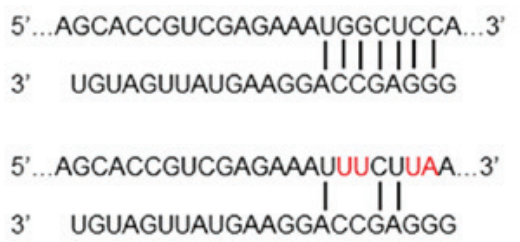

C

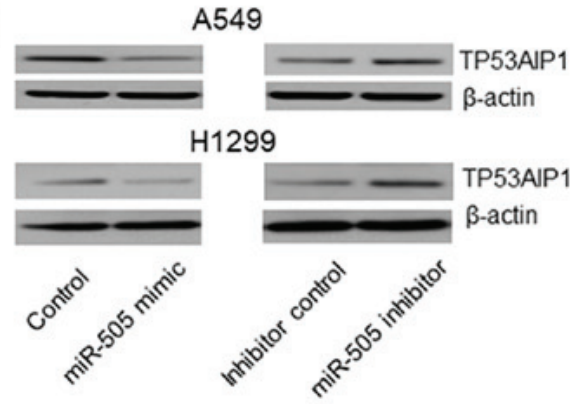

D

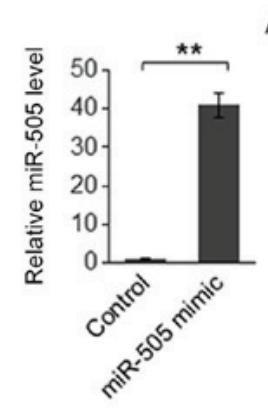

A549

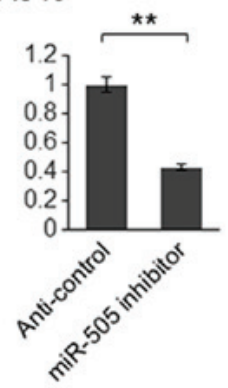

E

A549
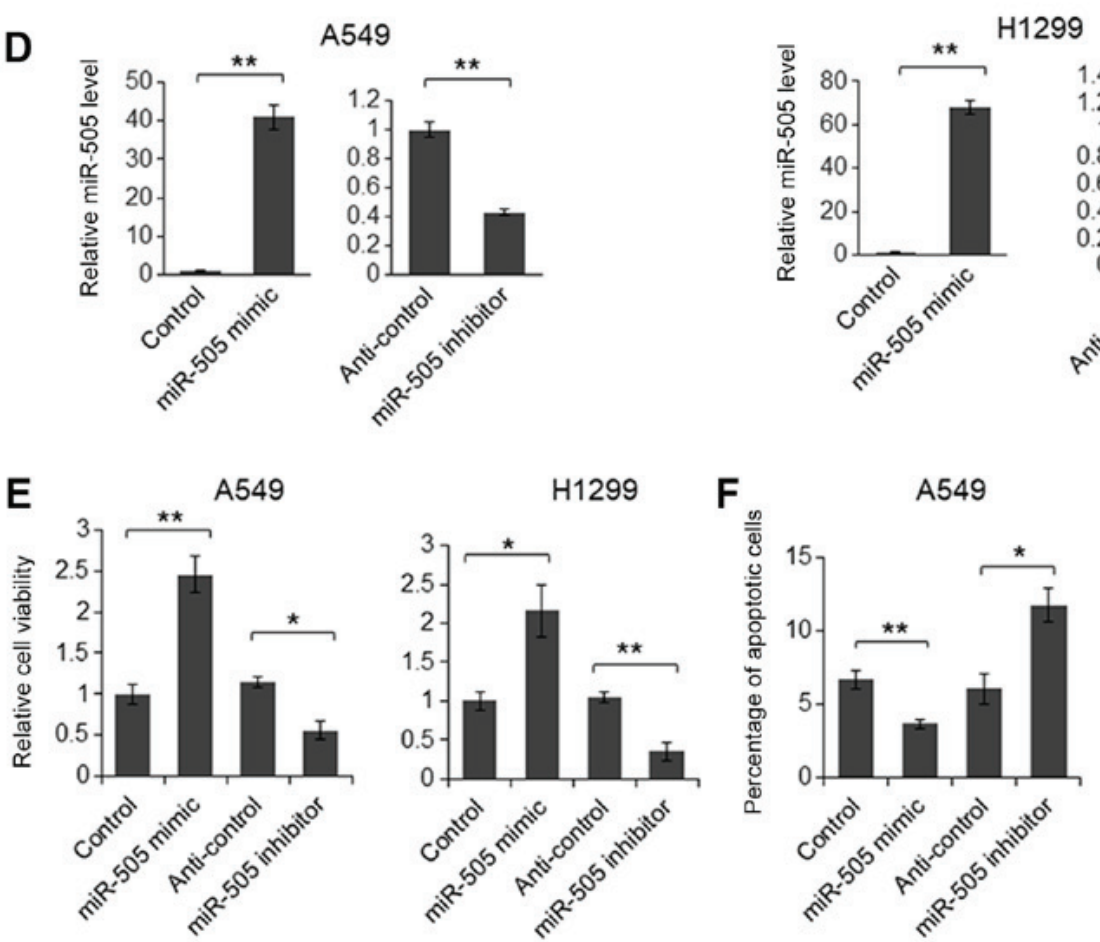

H1299
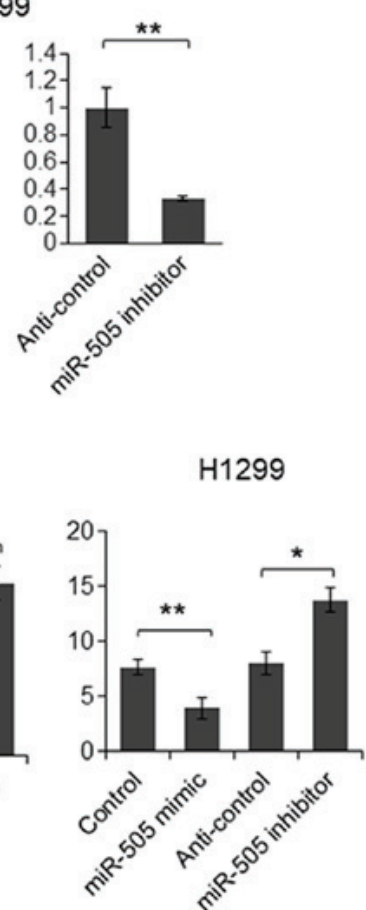

Figure 6. TP53AIP1 is a direct target of miR-505-5p. (A) The predicted target site of miR-505-5p in the TP53AIP1 3'-UTR, and the 4 nucleotide mutant sequence (red letters), are depicted. Results from the (B) dual luciferase assay and (C) immunoblotting are also depicted. (D) A reverse transcription-quantitative polymerase chain reaction assay was performed to determine the miR-505-5p level in miR-505 mimic- or inhibitor-transfected cells $72 \mathrm{~h}$ after transfection. (E) An MTT assay was performed to determine cell viability, while (F) flow cytometric analysis was performed to determine the percentage of apoptotic cells. Paired Student's t-test was used to analyze the results. Two-tailed $\mathrm{P}<0.05$ was considered to indicate a statistically significant difference. ${ }^{*} \mathrm{P}<0.05$ and ${ }^{* *} \mathrm{P}<0.01$, compared with the controls. TP53AIP1, tumor protein P53-regulated apoptosis-inducing protein 1; LA, lung adenocarcinoma; miRNA, microRNA; WT, wild-type; MUT, mutated; UTR, untranslated region.

respectively, of miR-505-5p in miR-505-5p mimic- or inhibitor-transfected A549 and H1299 cells were confirmed by RT-qPCR (Fig. 6D). These results revealed that miR-505-5p inhibited endogenous TP53AIP1 expression by targeting its mRNA 3'-UTR. To understand the biological function of miR-505-5p, the miR-505-5p mimic or the inhibitor was transfected into A549 and H1299 cells. A significant increase in the viability of the miR-505-5p-overexpressed cells and a significant decrease in the viability of the miR-505-5p knockdown cells were observed (Fig. 6E). Furthermore, cell apoptosis was significantly suppressed in the presence of the miR-505-5p mimic and significantly promoted by the miR-505-5p inhibitor in A549 and H1299 cells, indicating that miR-505-5p functions as an oncogene in lung cancer cells (Fig. 6F).

To further assess the functional role of an increased level of miR-505-5p in EVs, EVs were isolated from the plasma samples of 10 patients with LA and 10 control subjects. A549 and H1299 cells were co-cultured with the plasma EVs of the patients and the controls, separately, for $48 \mathrm{~h}$, and the levels of cell viability and apoptosis were determined. As depicted in Fig. 7A, following co-culture with EVs from the patients with LA, the miR-505-5p 
A

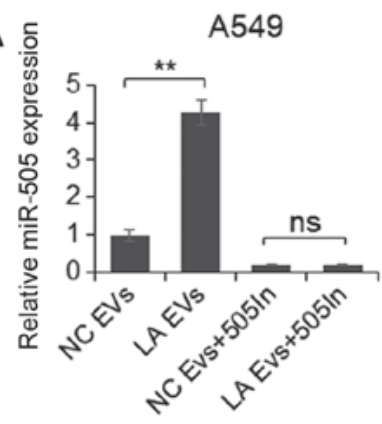

C

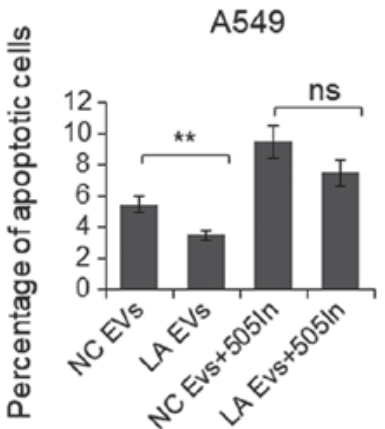

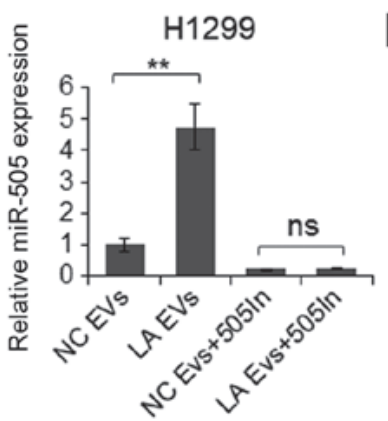
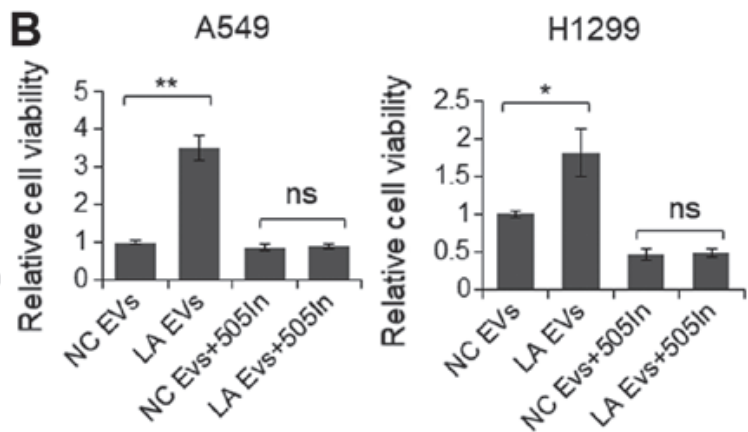

$\mathrm{H} 1299$

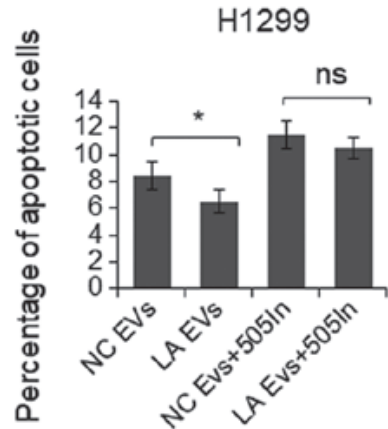

Figure 7. EVs from patients with LA promote cell viability and inhibit cell apoptosis by delivering miR-505-5p. (A) A549 and H1299 cells were co-cultured with EVs isolated from patients with LA or healthy NCs for $48 \mathrm{~h}$. Total RNA was extracted and the level of miR-505-5p was determined by reverse transcription-quantitative polymerase chain reaction. (B) A549 and H1299 cells were treated with the miR-505-5p inhibitor or control nucleotides, and then co-cultured with EVs from patients with LA and healthy NCs. Cell viability was detected after $48 \mathrm{~h}$ of co-culture. (C) A549 and H1299 cells were treated with the miR-505-5p inhibitor or control nucleotides, and then co-cultured with EVs from patients with LA and healthy NCs. Cell apoptosis was detected after $48 \mathrm{~h}$ of co-culture. Paired Student's t-test was used to analyze the results. Two tailed $\mathrm{P}<0.05$ was considered to indicate a statistically significant difference. ${ }^{*} \mathrm{P}<0.05$ and ${ }^{* *} \mathrm{P}<0.01$, compared with the NCs. LA, lung adenocarcinoma; EV, extracellular vesicle; NC, normal control; ns, not significant; 505In, miR-505-5p inhibitor.

levels in A549 and H1299 cells were significantly increased. Additionally, cell viability was significantly increased, and the apoptotic rate was significantly reduced (Fig. 7B and C). By contrast, when cells were first treated with the miR-505-5p inhibitor and subsequently co-cultured with EVs, the resultant miR-505-5p levels were revealed to be similar, and cell viability and apoptosis were not significantly altered, indicating further that miR-505-5p delivered by the EVs was the key regulator of cell viability and apoptosis.

\section{Discussion}

Tumor-derived EVs containing specific proteins and RNAs are attracting increasing interest as promising cancer biomarkers (32). These EVs are easily obtained from biological fluids, are highly stable and bear the characteristics of their parental cells. These molecules fulfill a variety of associated roles in key physiological and pathological activities, including the transportation of oncoproteins and tumor-specific miRNA molecules throughout the body (33). As such, they are considered as ideal biomarkers for cancer diagnosis and prognosis due to their high sensitivity and minimal invasiveness $(34,35)$. However, data regarding plasma EVs in LA are relatively rare, and are frequently conflicting (36-39,27-30). In the present study, the presence of altered levels of miRNAs in plasma EVs was firstly screened from 5 patients with LA and 5 healthy controls. A total of 10 candidate miRNAs were further examined in a larger population comprising 148 patients with
LA and 70 control subjects. The level of miR-505-5p was revealed to be increased, whereas that of miR-382-3p was reduced in the plasma EVs derived from the patients with LA. After performing statistical analysis, the levels of miR-505-5p and miR-382-3p were capable of being used to distinguish patients with LA from healthy controls, and had the potential to become a biomarker for early-stage LA diagnosis.

The human miR-505 gene is first transcribed into an 84 bp pre-miR-505, which is further processed into mature miRNAs, including miR-505-3p and miR-505-5p (40). miR-505-3p is the predominant miRNA, having a relative increased level, compared with miR-505-5p in different human cells (40). It has been reported that miR-505-3p functions as a tumor suppressor in endometrial cancer, osteosarcoma and hepatoma by targeting transforming growth factor- $\alpha$ and high mobility group box 1 (41-43). However, the function of miR-505-5p has yet to be fully elucidated. In the present study, it was revealed that only the miR-505-5p level was altered in the plasma and tumor tissues of patients. The role of miR-505-5p in lung cancer cell lines was subsequently examined, and it was demonstrated that miR-505-5p functions as an oncogene by promoting cell proliferation via the targeting of TP53AIP1. To the best of our knowledge, the present study is the first published study in which an investigation of the role of miR-505-5p in LA has partially uncovered the mechanism of miR-505-5p during the tumorigenesis of LA, also providing a novel biomarker for LA treatment. 
Chen et al (44) demonstrated that miR-382 expression is decreased in NSCLC tissue samples, particularly in patients with stage III/V cancer and metastatic tumors (44). However, in the present study, altered miR-382 levels in the tumor samples from patients with LA were not identified. This difference may be attributed to having a different cohort of research subjects. The present study was focused only on patients with early-stage LA, whereas that of Chen et al (44) detected the level of miR-382 in tumors from all patients with NSCLC. These contrasting results also indicate that miR-382 may have the potential for staging lung cancer, a possibility that should be investigated further in patients with different types and stages of NSCLC.

A number of groups have identified certain candidate miRNAs that have the potential for LA diagnosis, although whether these miRNAs are functional remains unclear (45-47). Therefore, functional studies were performed to assess the role of miR-505-5p in EVs. Following co-culture, it was confirmed that miR-505-5p in EVs could be delivered into cancer cells. Furthermore, the EV-delivered miR-505-5p retained its functional properties, promoting proliferation and repressing cell apoptosis, indicating that EV miR-505-5p serves an important role in cell-cell communication.

A few limitations of the present study should be acknowledged. Firstly, the data included the Chinese Han population, and the roles of miR-505-5p and miR-382-3p in other populations require further evaluation. Secondly, although the miR-505-5p inhibitor almost rescued the function of EVs following co-culture, proteins and other miRNAs in EVs may also have contributed to the obtained data.

In conclusion, miR-505-5p in EVs was identified as a candidate molecule for early-stage LA detection, and its function in association with LA tumorigenesis has been partially uncovered. These observations provide novel insights into LA development, early diagnosis and treatment.

\section{Acknowledgements}

Not applicable.

\section{Funding}

The present study was supported by Open Research Fund of Key Laboratory of Cell Proliferation and Regulation Biology, Ministry of Education, College of Life Sciences, Beijing Normal University (Beijing, China).

\section{Availability of data and materials}

The datasets used and/or analyzed during the current study are available from the corresponding author on reasonable request.

\section{Authors' contributions}

GA and HF designed the experiment. YL, YH, YJ and YW collected the clinical samples. HF, HL and YG extracted the exosomes. HF conducted the functional study. HL and YG participated in the clinical data acquisition, analysis and interpretation. GA and HF analyzed the results and prepared the manuscript.

\section{Ethics approval and consent to participate}

The present study was approved by the Human Basic and Clinical Research Ethics Committee of Fuxing Hospital (approval no. 2018FXHEC-KY-19). All participants provided written informed consent prior to sampling.

\section{Patients consent for publication}

All the patients involved in the present study provided written informed consent for the publication of any associated data and accompanying images.

\section{Competing interests}

The authors declare that they have no competing interests.

\section{References}

1. Bray F, Ferlay J, Soerjomataram I, Siegel RL, Torre LA and Jemal A: Global cancer statistics 2018: GLOBOCAN estimates of incidence and mortality worldwide for 36 cancers in 185 countries. CA Cancer J Clin 68: 394-424, 2018.

2. Zhou C: Lung cancer molecular epidemiology in China: Recent trends. Transl Lung Cancer Res 3: 270-279, 2014.

3. Chen Z, Fillmore CM, Hammerman PS, Kim CF and Wong KK: Non-small-cell lung cancers: a heterogeneous set of diseases. Nat Rev Cancer 14: 535-546, 2014.

4. Li Q, Liu M, Ma F, Luo Y, Cai R, Wang L, Xu N and Xu B: Circulating miR-19a and miR-205 in serum may predict the sensitivity of luminal A subtype of breast cancer patients to neoadjuvant chemotherapy with epirubicin plus paclitaxel. PLoS One 9: e104870, 2014

5. Bach PB, Mirkin JN, Oliver TK, Azzoli CG, Berry DA, Brawley OW, Byers T, Colditz GA, Gould MK, Jett JR, et al: Benefits and harms of CT screening for lung cancer: a systematic review. JAMA 307: 2418-2429, 2012.

6. SaghirZ,Dirksen A,AshrafH,BachKS,BrodersenJ,Clementsen PF, Døssing M, Hansen H, Kofoed KF, Larsen KR, et al: Lung cancer screening with low dose $\mathrm{CT}$ requires careful consideration. Ugeskr Laeger 176: pii: V06140341, 2014 (In Danish).

7. Holdenrieder S, Wehnl B, Hettwer K, Simon K, Uhlig S and Dayyani F: Carcinoembryonic antigen and cytokeratin-19 fragments for assessment of therapy response in non-small cell lung cancer: A systematic review and meta-analysis. Br J Cancer 116: 1037-1045, 2017.

8. Okamura K, Takayama K, Izumi M, Harada T, Furuyama K and Nakanishi Y: Diagnostic value of CEA and CYFRA 21-1 tumor markers in primary lung cancer. Lung cancer 80: 45-49, 2013.

9. Chen F, Wang XY, Han XH, Wang H and Qi J: Diagnostic value of Cyfra21-1, SCC and CEA for differentiation of early-stage NSCLC from benign lung disease. Int J Clin Exp Med 8: 11295-11300, 2015.

10. Reck M and Rabe KF: Precision Diagnosis and Treatment for Advanced Non-Small-Cell Lung Cancer. N Engl J Med 377: 849-861, 2017.

11. Zaborowski MP, Balaj L, Breakefield XO and Lai CP: Extracellular Vesicles: Composition, Biological Relevance, and Methods of Study. Bioscience 65: 783-797, 2015.

12. Vlassov AV, Magdaleno S, Setterquist R and Conrad R: Exosomes: current knowledge of their composition, biological functions, and diagnostic and therapeutic potentials. Biochim Biophys Acta 1820: 940-948, 2012.

13. Trinchieri G: Cancer and inflammation: an old intuition with rapidly evolving new concepts. Annu Rev Immunol 30: 677-706, 2012.

14. Pereira ER, Jones D, Jung K and Padera TP: The lymph node microenvironment and its role in the progression of metastatic cancer. Semin Cell Dev Biol 38: 98-105, 2015.

15. O'Loghlen A: Role for extracellular vesicles in the tumour microenvironment. Philos Trans R Soc Lond B Biol Sci 373: 373, 2018.

16. Wang Y, Yi J, Chen X, Zhang Y, Xu M and Yang Z: The regulation of cancer cell migration by lung cancer cell-derived exosomes through TGF- $\beta$ and IL-10. Oncol Lett 11: 1527-1530, 2016. 
17. Tang Y, Cui Y, Li Z, Jiao Z, Zhang Y, He Y, Chen G, Zhou Q, Wang W, Zhou X, et al: Radiation-induced miR-208a increases the proliferation and radioresistance by targeting p21 in human lung cancer cells. J Exp Clin Cancer Res 35: 7, 2016.

18. Lewis BP, Burge CB and Bartel DP: Conserved seed pairing, often flanked by adenosines, indicates that thousands of human genes are microRNA targets. Cell 120: 15-20, 2005.

19. Ma J and Li X: MicroRNAs are involved in the toxicity of microcystins. Toxin Rev 36: 11, 2017.

20. Ma J, Li Y, Yao L and Li X: Analysis of MicroRNA Expression Profiling Involved in MC-LR-Induced Cytotoxicity by High-Throughput Sequencing. Toxins (Basel) 9: 9, 2017.

21. Zhao Y, Xie P and Fan H: Genomic profiling of microRNAs and proteomics reveals an early molecular alteration associated with tumorigenesis induced by MC-LR in mice. Environ Sci Technol 46: 34-41, 2012.

22. Maes OC, Chertkow HM, Wang E and Schipper HM: MicroRNA Implications for Alzheimer Disease and other Human CNS Disorders. Curr Genomics 10: 154-168, 2009.

23. Xu J, Li Y, Wang F, Wang X, Cheng B, Ye F, Xie X, Zhou C and Lu W: Suppressed miR-424 expression via upregulation of target gene Chk1 contributes to the progression of cervical cancer. Oncogene 32: 976-987, 2013

24. Farazi TA, Hoell JI, Morozov P and Tuschl T: MicroRNAs in human cancer. Adv Exp Med Biol 774: 1-20, 2013

25. Detterbeck FC, Boffa DJ, Kim AW and Tanoue LT: The Eighth Edition Lung Cancer Stage Classification. Chest 151: 193-203, 2017.

26. Coglitore D, Edwardson SP, Macko P, Patterson EA and Whelan M: Transition from fractional to classical Stokes-Einstein behaviour in simple fluids. R Soc Open Sci 4: 170507, 2017.

27. Livak KJ and Schmittgen TD: Analysis of relative gene expression data using real-time quantitative PCR and the $2-\Delta \Delta C T$ method. Methods 25: 402-408, 2001.

28. Raposo G and Stoorvogel W: Extracellular vesicles: Exosomes, microvesicles, and friends. J Cell Biol 200: 373-383, 2013.

29. Okamura S, Arakawa H, Tanaka T, Nakanishi H, Ng CC, Taya Y, Monden M and Nakamura Y: p53DINP1, a p53-inducible gene, regulates p53-dependent apoptosis. Mol Cell 8: 85-94, 2001.

30. Yamashita S, Chujo M, Miyawaki M, Tokuishi K, Anami K, Yamamoto S and Kawahara K: Combination of p53AIP1 and survivin expression is a powerful prognostic marker in non-smal cell lung cancer. J Exp Clin Cancer Res 28: 22, 2009.

31. Yamashita SI, Masuda Y, Yoshida N, Matsuzaki H, Kurizaki T, Haga Y, Ikei S, Miyawaki M, Kawano Y, Chujyo M and Kawahara K: p53AIP1 expression can be a prognostic marker in non-small cell lung cancer. Clin Oncol (R Coll Radiol) 20 148-151, 2008.

32. Verma M, Lam TK, Hebert E and Divi RL: Extracellular vesicles: Potential applications in cancer diagnosis, prognosis, and epidemiology. BMC Clin Pathol 15: 6, 2015.

33. Liu S, Zhan Y, Luo J, Feng J, Lu J, Zheng H, Wen Q and Fan S: Roles of exosomes in the carcinogenesis and clinical therapy of non-small cell lung cancer. Biomed Pharmacother 111: 338-346, 2018.
34. Bonjoch L, Gironella M, Iovanna JL and Closa D: REG3 modifies cell tumor function by impairing extracellular vesicle uptake. Sci Rep 7: 3143, 2017.

35. Mrowczynski OD, Madhankumar AB, Slagle Webb B, Lee SY, Zacharia BE and Connor JR: HFE genotype affects exosome phenotype in cancer. Biochim Biophys Acta Gen Subj 1861: 1921-1928, 2017

36. Chen X, Ba Y, Ma L, Cai X, Yin Y, Wang K, Guo J, Zhang Y, Chen J, Guo X, et al: Characterization of microRNAs in serum: a novel class of biomarkers for diagnosis of cancer and other diseases. Cell Res 18: 997-1006, 2008.

37. Lin Q, Mao W, Shu Y, Lin F, Liu S, Shen H, Gao W, Li S and Shen D: A cluster of specified microRNAs in peripheral blood as biomarkers for metastatic non-small-cell lung cancer by stem-loop RT-PCR. J Cancer Res Clin Oncol 138: 85-93, 2012.

38. Wang ZX, Bian HB, Wang JR, Cheng ZX, Wang KM and De W: Prognostic significance of serum miRNA-21 expression in human non-small cell lung cancer. J Surg Oncol 104: 847-851, 2011.

39. Silva J, Garcia V, Zaballos A, Provencio M, Lombardía L, Almonacid L, García JM, Domínguez G, Peña C, Diaz R, et al: Vesicle-related microRNAs in plasma of nonsmall cell lung cancer patients and correlation with survival. Eur Respir J 37: 617-623, 2011.

40. Kozomara A and Griffiths-Jones S: miRBase: Annotating high confidence microRNAs using deep sequencing data. Nucleic Acids Res 42 (D1): D68-D73, 2014.

41. Chen S, Sun KX, Liu BL, Zong ZH and Zhao Y: MicroRNA-505 functions as a tumor suppressor in endometrial cancer by targeting TGF- $\alpha$. Mol Cancer 15: 11, 2016.

42. Liu YJ, Li W, Chang F, Liu JN, Lin JX and Chen DX: MicroRNA-505 is downregulated in human osteosarcoma and regulates cell proliferation, migration and invasion. Oncol Rep 39: 491-500, 2018.

43. Lu L, Qiu C, Li D, Bai G, Liang J and Yang Q: MicroRNA-505 suppresses proliferation and invasion in hepatoma cells by directly targeting high-mobility group box 1 . Life Sci 157: 12-18, 2016.

44. Chen T, Ren H, Thakur A, Yang T, Li Y, Zhang S, Wang T and Chen M: miR-382 inhibits tumor progression by targeting SETD8 in non-small cell lung cancer. Biomed Pharmacother 86: 248-253, 2017.

45. Zhou X, Wen W, Shan X, Zhu W, Xu J, Guo R, Cheng W, Wang F, Qi LW, Chen Y, et al: A six-microRNA panel in plasma was identified as a potential biomarker for lung adenocarcinoma diagnosis. Oncotarget 8: 6513-6525, 2017.

46. Feng M, Zhao J, Wang L and Liu J: Upregulated Expression of Serum Exosomal microRNAs as Diagnostic Biomarkers of Lung Adenocarcinoma. Ann Clin Lab Sci 48: 712-718, 2018.

47. Maemura K, Watanabe K, Ando T, Hiyama N, Sakatani T, Amano Y, Kage H, Nakajima J, Yatomi Y, Nagase T, et al: Altered editing level of microRNAs is a potential biomarker in lung adenocarcinoma. Cancer Sci 109: 3326-3335, 2018. 